\title{
SCIDiC
}

\author{
International Journal of Dentistry and Oral Science (IJDOS) \\ ISSN: $2377-8075$
}

\section{Awareness Of Management Of Children With HIV Among Dental Students}

Research Article

\author{
Dhanraj Ganapathy ${ }^{1 *}$, Kuzhalvai Mozhi ${ }^{2}$
}

${ }^{1}$ Professor and Head of Department, Department of Prosthodontics, Saveetha Dental College, Chennai Saveetha Institute Of Medical and Technical Sciences, Chennai-600077, Tamilnadu, India.

${ }^{2}$ Undergraduate student, Department of Prosthodontics, Saveetha Dental College, Chennai Saveetha Institute Of Medical and Technical Sciences, Chennai-600077, Tamilnadu, India.

\section{Abstract}

Introduction: The human immunodeficiency virus (HIV) is grouped to the genus Lentivirus with in the family of Retroviridae, subfamily Orthoretrovirinae. On the basis of genetic characteristics and differences in the viral antigens, HIV is classified in to the types 1 and 2 (HIV-1, HIV-2) (1). Before 1996, few antiretroviral treatment options for HIV-1 infection existed. The clinical management of HIV-1 largely consisted of prophylaxis against common opportunistic pathogens and managing AIDS-related illnesses.

Aim: The aim of the study was to assess the knowledge and awareness of management of HIV children among dental students.

Materials and Method: A cross sectional questionnaire was designed and distributed to 100 dental students. Questionnaire includes email address, questions about primary prophylaxis for HIV children, why prophylaxis is given, alternative of prophylactic drug, and their side effects. Data was collected, statistically analysed and results were obtained.

Results: The results observed in our study showed that awareness and knowledge of management of children with HIV among dental students were high. But Dental students were not aware of side effect of primary prophylactic drug Cotrimoxazole and their purpose in HIV infected children, and also the diagnostic test which is recommended for children with HIV. Most of the dental students not aware of term inflammatory immune reconstitution syndrome.

Conclusion: Various awareness programs should be conducted to educate more about management of children with HIV and prophylactic measures for HIV infected children among the dental students.

Keywords: Human Immunodeficiency Virus; Antiretroviral Therapy; Primary Prophylaxis; Immunisation; Cotrimoxazole.

\section{Introduction}

The human immunodeficiency virus (HIV) is grouped to the genus Lentivirus with in the family of Retroviridae, subfamily Orthoretrovirinae. On the basis of genetic characteristics and differences in the viral antigens, HIV is classified into the types 1 and 2 (HIV-1, HIV-2) [1]. Before 1996, few antiretroviral treatment options for HIV-1 infection existed. The clinical management of HIV-1 largely consisted of prophylaxis against common opportunistic pathogens and managing AIDS-related illnesses. The treatment of HIV-1 infection was revolutionized in the mid-1990s by the development of inhibitors of the reverse transcriptase and protease, two of three essential enzymes of HIV-1, and the introduction of drug regimens that combined these agents to enhance the overall efficacy and durability of therapy. Since the first HIV-1 specific antiviral drugs were given as monotherapy in the early 1990s, the standard of HIV-1 care evolved to include the administration of a cocktail or combination of antiretroviral agents (ARVs). The advent of combination therapy, also known as HAART, for the treatment of HIV-1 infection was seminal in reducing the morbidity and mortality associated with HIV-1 infection and AIDS [2-4]. Vertical transmission of HIV, either

\section{*Corresponding Author:}

Dhanraj Ganapathy

Professor and Head of Department, Department of Prosthodontics, Saveetha Dental College, Chennai Saveetha Institute Of Medical and Technical Sciences, Chennai-600077, Tamilnadu, India.

Email Id: dhanrajmganapathy@yahoo.co.in

Received: February 25, 2021

Accepted: March 04, 2021

Published: March 18, 2021

Citation: Dhanraj Ganapathy, Kuzhalvai Mozhi. Awareness Of Management Of Children With HIV Among Dental Students. Int J Dentistry Oral Sci. 2021;08(03):2099-2103. doi: http://dx.doi.org/10.19070/2377-8075-21000414

Copyright: DhanrajGanapathy ${ }^{\circ} 2021$. This is an open-access article distributed under the terms of the Creative Commons Attribution License, which permits unrestricted use, distribution and reproduction in any medium, provided the original author and source are credited. 
in utero, intrapartumorpost-natally through breastfeeding, is the predominant route for acquisition of HIV infection in children [5]. Since2010, there has been an 18\% decrease in the incidence of new HIV infections globally. Rarely, children born to HIVuninfected women may acquire HIV by horizontal transmission [6]. This may occur through healthcare-associated transmission by infusion of HIV-contaminated blood or blood products, re-use of contaminated needles/syringes or other medical equipment, and ingestion of HIVin expressed breastmilk in neonatal units [7]. Alternatively, community-acquired, horizontal HIV transmissionmay occur following surrogate breastfeeding or 'wet nursing' by awoman with HIV, pre-mastication of food, and sexual abuse [8, 9]. In most instances of horizontal HIV acquisition in children, the exact route of transmission is difficult to determine owing to the time elapsedbetween the HIV-exposure event/s and confirmation of HIV in the child [6]. These events require thorough investigation to establish the most likely route of transmission, although inmany cases this may be undetermined.

HIV infection is particularly aggressive in children-without access to treatment, more than half of HIV-infected infants die before the age of 2 years, with a median survival of only 23 month [10]. Malnutrition affects over one-quarter of under $5 \mathrm{~s}$ in the developing world and is thought to contribute to one-third of deaths in this age group-estimated at 1-2 million deaths per year [11]. When compared with HIV-negative counterparts, HIV-infected children (including asymptomatic children) have additional nutritional requirements to ensure normal growth and development and require high-energy, high-protein, nutrient-dense diets. Calorie intake needs to be increased, with children requiring up to $150 \%$ of the recommended daily allowance of calories, and micronutrient requirement is up to five times that of an HIV-negative child It is recommended that-compared with HIV-negative childrenasymptomatic HIV-positive children have a 10\% increased calorie intake, which is best given through additional household foods, as part of a balanced, varied diet [12]. Abnormalities in growth and metabolism are common in children infected with HIV. Poor growth was among the first manifestations of HIV infection to be recognized in children and had a significant effect on shortterm survival [13]. Aim of the study is to assess the knowledge and awareness of management of children with HIV among dental students.

\section{Materials and Methods}

The study was conducted during the academic year december 2020 among the dental students.

Figure 1. Are you aware that HIV can occur in children?

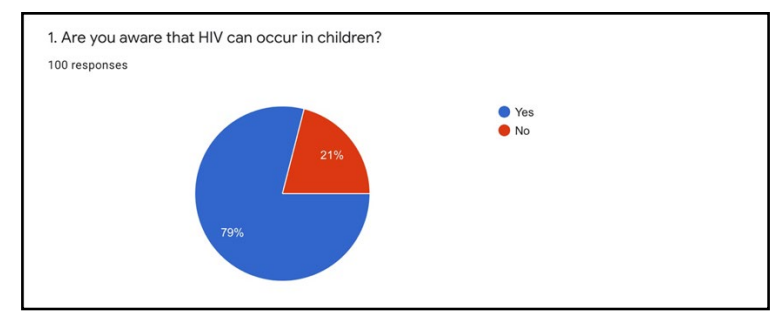

Among the study population, majority (47\%) aware that primary management of HIV infected children is family centred care where as $28 \%$ of the study population told that primary management of HIV infected children is antiretroviral therapy and $25 \%$ of the study population told that primary management of HIV infected children is immunisation.

Figure 2. Primary management of HIV in children is.

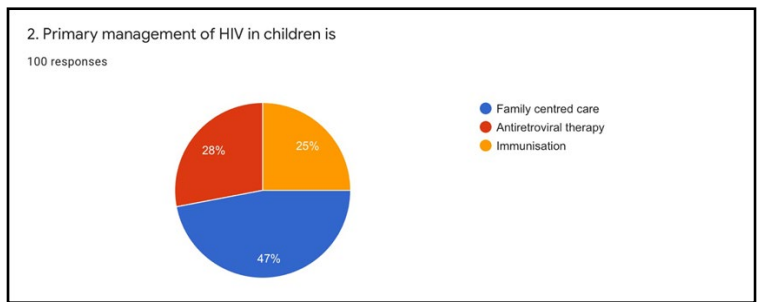

Among the study population, majority (57\%) aware that HIV infection can be determined in HIV exposed infants before age of 18 months where as $23 \%$ of the study population told that HIV infection can be determined in HIV exposed infants before age of 16 months and $20 \%$ of the study population told that HIV infection can be determined in HIV exposed infants before age of 10 months.

Figure 3. When will you determine HIV infection in HIV exposed infants (infants born to HIV + positivemother)?

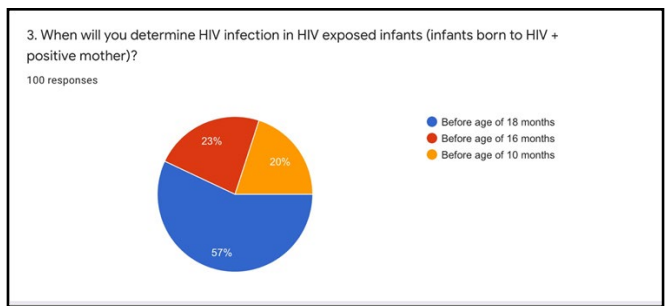

Among the study population, majority $(60 \%)$ aware that rotavirus and pneumococcal immunisation is the additional immunisation given to HIV infected children apart from routine immunisation whereas $40 \%$ of the study population told that live attenuated influenza vaccine is the additional immunisation given to HIV infected children apart from routine immunisation 
Figure 4. What is the additional immunisation given to HIV infected children apart from routine immunisation?

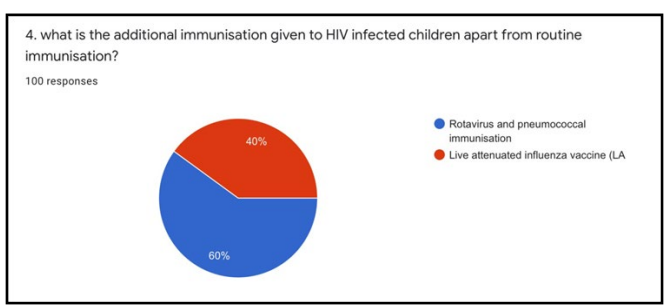

Among the study population, majority $(66 \%)$ aware that Cotrimoxazole is the primary prophylaxis given to prevent HIV associated infection in children where as $19 \%$ of the study population told that efavirenz is the primary prophylaxis given to prevent HIV associated infection in children and $15 \%$ of the study population told that zidovudine is the primary prophylaxis given to prevent HIV associated infection in children.

Figure 5. What is the primary prophylaxis given to prevent HIV associated infection in children?

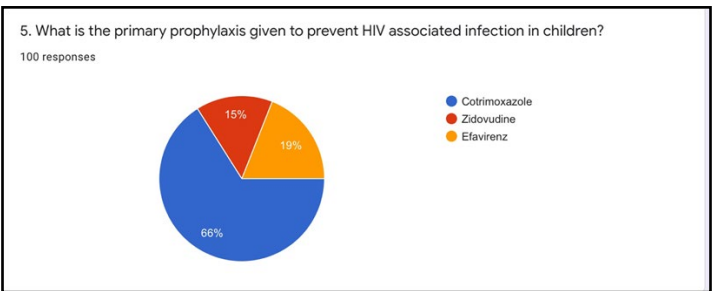

Among the study population, majority (56\%) aware that dapsone is the alternative drug to Cotrimoxazole whereas $44 \%$ of the study population told that zidovudine is the alternative drug to Cotrimoxazole.

Figure 6. What is the alternative drug to Cotrimoxazole?

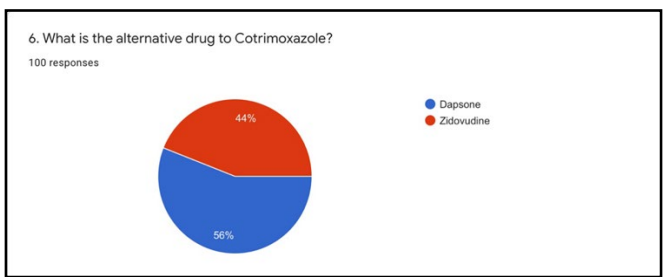

Among the study population, $50 \%$ of the study population told that Cotrimoxazole prophylaxis is given to prevent pneumocystis pneumonia and $50 \%$ of the study population told that Cotrimoxazole prophylaxis is given to cure HIV permanently.

Figure 7. Why is Cotrimoxazole prophylaxis given?

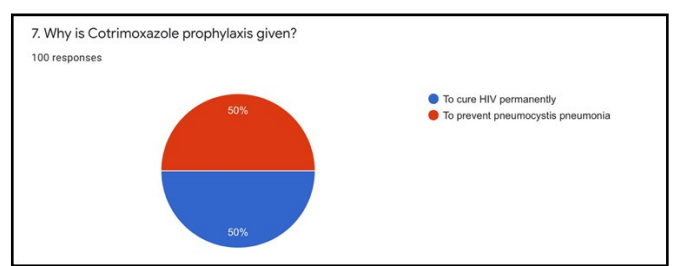

Among the study population, $41 \%$ of the study population told that hepatotoxicity is important side effect to be considered while taking Cotrimoxazole where as only $38 \%$ of the study population aware that skin rash is the important side effect to be considered while taking Cotrimoxazole and $21 \%$ of the study population told that diarrhoea is the important side effect to be considered while taking Cotrimoxazole.

\section{Study Sample Size:}

The descriptive cross sectional study was based among 100 dental students.

\section{Inclusion and Exclusion Criteria:}

Dental students who were studying $2^{\text {rd }}, 3^{\text {rd }}$ year, and final year. Dental students who are not willing to participate were excluded in this study.

\section{Questionnaire:}

The questionnaire was not targeted at a specific group but all dental students in general to assess their knowledge of management of HIV infected children among dental students. A validated questionnaire was distributed among the dental students in this study. This included questions about primary prophylaxis given for HIV infected children, alternative to primary prophylactic drug, their side effects among dental students. The data extracted were tabulated, statistically analysed and results were obtained using SPSS software.

\section{Results}

Among the study population, majority (79\%) aware that HIV can also occur in children whereas $21 \%$ of the study population not aware that HIV can occur in children. 
Figure 8. What is the important side effects of Cotrimoxazole?

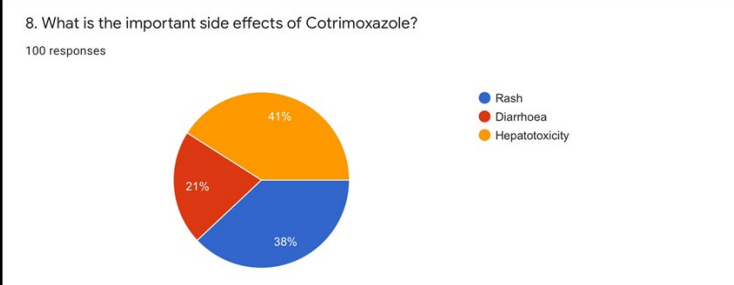

Among the study population, majority (34\%) aware that polymerase chain reaction (PCR) is the test used for diagnosing HIV infection in children where as $33 \%$ of the study population told that western blot and $33 \%$ of the study population told ELISA is the test used for diagnosing HIV infection in children.

Figure 9. What is the test used for diagnosing HIV infection in children?

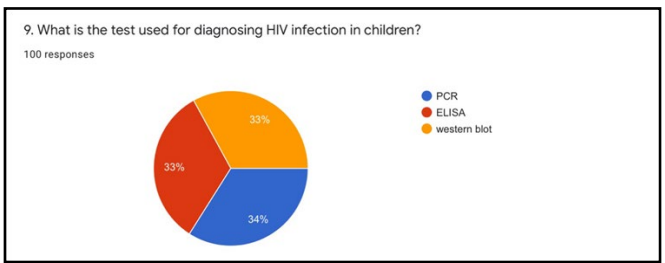

Among the study population, majority (55\%) aware that 2 nucleoside reverse transcriptase inhibitors +1 non nucleoside reverse transcriptase inhibitors is the standard regimen for first line antiretroviral therapy in children with HIV where as $29 \%$ of the study population told that 1 nucleoside reverse transcriptase inhibitors +1 non nucleoside reverse transcriptase inhibitors is the standard regimen for first line antiretroviral therapy in children with HIV and $16 \%$ of the study population told that 1 nucleoside reverse transcriptase inhibitors +1 protease inhibitors is the standard regimen for first line antiretroviral therapy in children with HIV.

Figure 10. What is the standard regimen for first line ART in children with HIV?

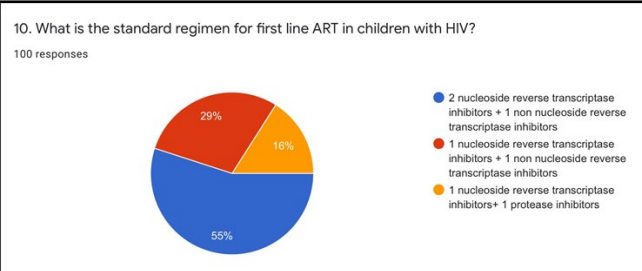

Among the study population, majority (64\%) aware of inflammatory immune reconstitution syndrome whereas $36 \%$ of the study population not aware of inflammatory immune reconstitution syndrome.

Figure 11. Are you aware of inflammatory immune reconstitution syndrome?

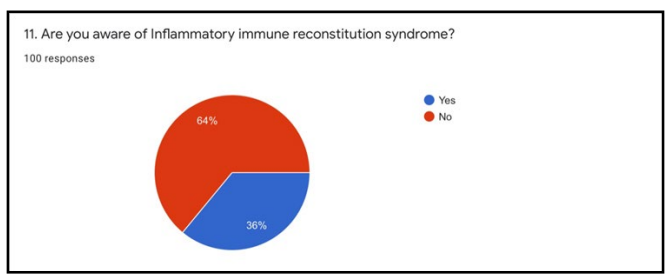

\section{Discussion}

Ideally, HIV infection in children is identified by the presence of the virus in blood or tissues, confirmed by culture or other laboratory detection methods. However, current tests including culture for detecting the virus or its antigens are not standardized and are not readily available. Detection of specific antibody to the virus is a sensitive and specific indicator of HIV infection in adults [14-16]. Similar studies involving children have not been reported. Most of the consultants believed that passively transferred maternal HIV antibody could sometimes persist for up to 15 months.

For this reason, two definitions for infection in children are needed: one for infants and children up to 15 months of age who have been exposed to their infected mothers perinatally, and another for older children with perinatal infection and for infants and children of all ages acquiring the virus through other means. Infants and children under 15 months of age with perinatal infectionInfection in infants and children up to 15 months of age who were exposed to infected mothers in the perinatal period may be defined by one or more of the following: 1) the identification of the virus in blood or tissues, 2) the presence of HIV antibody as indicated by a repeatedly reactive screening test (e.g., enzyme immunoassay) plus a positive confirmatory test (e.g., Westem blot, immunofluorescence assay) in an infant or child who has abnormal immunologic test results indicating both humoral and cellular immunodeficiency (increased immunoglobulin levels, depressed $\mathrm{T}$ 4 IT -helper absolute cell count, absolute lymphopenia, decreased $\mathrm{T} 4 / \mathrm{TB}$ ratio) and who meets the requirements of one or more of the subclasses listed under class P-2, or 3) the confirmation that a child's symptoms meet the previously published CDC case definition for pediatric AIDS [17, 18].

The infection status of other perinatally exposed seropositive 
infants and children up to 15 months of age who lack one of the above immunologic or clinical criteria is indeterminate. These infants should be followed up for HIV-related illness, and they should be tested at regular intervals for persistence of antibody to HIV. Infants and children who become seronegative. are virusculture negative (if blood or tissue samples are cultured), and continue to have no clinical or laboratory-confirmed abnormalities associated with HIV infection are unlikely to be infected.

Older children with perinatal infection and children with HIV infection acquired through other modes of transmission - H1V infection in these children is defined by one Or more of the following: 1) the identification of virus in blood or tissues. 2) the presence of HIV antibody (positive screening test plus confirmatory test) regardless of whether immunologic abnormalities or signs or symptoms are present, or 3) the confirmation that the child's symptoms meet the previously published CDC case definition for pediatric AIDS. These definitions apply to children under 13 years of age $[19,20]$.

\section{Conclusion}

The results observed in our study showed that awareness and knowledge of management of children with HIV among dental students were high. But Dental students were not aware of side effect of primary prophylactic drug Cotrimoxazole and their purpose in HIV infected children, and also the diagnostic test which is recommended for children with HIV. Most of the dental students not aware of term inflammatory immune reconstitution syndrome. Various awareness programs should be conducted to educate more about management of children with HIV and prophylactic measures for HIV infected children among the dental students.

\section{References}

[1]. Luciw PA. Human immunodeficiency viruses and their replication; in Fields BN (ed): Virology, 3rd edn. Philadelphia, Lippincott-Raven, 1996; 18811952.

[2]. Collier AC, Coombs RW, Schoenfeld DA, Bassett RL, Timpone J, Baruch A, et al. Treatment of human immunodeficiency virus infection with saquinavir, zidovudine, and zalcitabine. AIDS Clinical Trials Group. N Engl J Med.1996; 334: 1011-1017.PubmedPMID: 8598838.

[3]. D'Aquila RT, Hughes MD,JohnsonVA,FischlMA,Sommadossi JP, LiouSH, et al. Nevirapine,zidovudine,anddidanosinecompared with zidovudine and didanosine in patients with HIV-1 infection. A randomized, double-blind, placebocontrolled trial. National Institute of Allergy and Infectious Diseases AIDS Clinical Trials Group Protocol 241 Investigators. Ann Intern Med.1996;124: 1019-1030.

[4]. Staszewski S, Miller V, Rehmet S, Stark T, De Crée J, De Brabander M, Peeters M, Andries K, Moeremans M, De Raeymaeker M, Pearce G, Van den Broeck R, Verbiest W, Stoffels P. Virological and immunological analysis of a triple combination pilot study with loviride, lamivudine and zidovudine in HIV-1-infected patients. AIDS. 1996 May;10(5):F1-7. PubmedPMID: 8724034 .

[5]. Cotton MF, Rabie H. HIV outbreak in children in Pakistan: localised or morewidespread?. Lancet Infect Dis 2020;20(3):269-70.PubmedPMID: 31866330.

[6]. Vaz P, Pedro A, Le Bozec S, Macassa E, Salvador S, Biberfeld G, et al. Nonve rtical,nonsexualtransmission of human immunodeficiency virus in children. Pediatr Infect Dis J2010;29(3):271-4.PubmedPMID: 20016396.

[7]. Cotton MF, Marais BJ, Andersson MI, Eley B, Rabie H, Slogrove AL, Dramowski A, Schaaf HS, Mehtar S. Minimizing the risk of non-vertical, nonsexual HIV infection in children--beyond mother to child transmission. J Int AIDS Soc. 2012 Nov 15;15(2):17377. Pubmed PMID: 23199798.

[8]. Shisana O, Connolly C, Rehle TM, Mehtar S, Dana P. HIV risk exposure among South African children in public health facilities. AIDS Care. 2008 Aug;20(7):755-63. Pubmed PMID: 18728983.

[9]. Maritz ER, Kidd M, Cotton MF. Premasticating food for weaning African infants: apossible vehicle for transmission of HIV. Pediatrics 2011;128(3):e579-590.Pubmed PMID: 21873699.

[10]. Brahmbhatt H, Kigozi G, Wabwire-Mangen F, Serwadda D, Lutalo T, Nalugoda $\mathrm{F}$, et al. Mortality in HIV-infected and uninfected children of HIVinfected and uninfected mothers in rural Uganda. J Acquir Immune DeficSyndr 2006;41:504-8. Pubmed PMID: 16652060.

[11]. United Nations. Millenium Development Goals Report. 2008.

[12]. Merchant RH, Lala MM. Common clinical problems in children living with HIV/AIDS: systemic approach. Indian J Pediatr 2012;79:1506-13.PubmedPMID: 23015361.

[13]. Oleske J, Minnefor A, Cooper R, Thomas K, dela Cruz A, Ahdieh H, et al. Immune deficiency syndrome in children. Jama. 1983 May 6;249(17):23459.

[14]. Bureau of the Census. Money. income of households. families. and persons in the United States: 1980. Washington. DC: US Department of Commerce. 1982. (Current population reports; series P-60; no 1321.

[15]. Black L. David RJ. Brouillette RT. Hunt CEo Effects of birth weight and ethnicity on incidence of sudden infant death syndrome. J Pediatr 1986;108:209-14

[16]. Babson SG, Clarke NG. Relationship between infant death and maternal age. Comparison of sudden infant death incidence with other causes of infant mortality. J Pediatr. 1983 Sep;103(3):391-3. PubmedPMID: 6886903.

[17]. CDC Years of potential life lost attributable to low birthweight-United States. 1980 birth cohort. MMWR 1986;35: 188-90. 195.

[18]. Froggatt P, Lynas MA, MacKenzie G. Epidemiology of sudden unexpected death in infants ('cot death') in Northern Ireland. British journal of preventive \& social medicine. 1971 Aug;25(3):119. Pubmed PMID:5564954.

[19]. Hogue CJ, Buehler JW, Strauss LT, Smith JC. Overview of the National Infant Mortality Surveillance (NIMS) project--design, methods, results. Public Health Rep. 1987 Mar-Apr;102(2):126-38. Pubmed PMID: 3104969.

[20]. National Center for Health Statistics. Advance report of final natality statistics. 1994. Monthly Vital Statistics Report 1986;35:17-8. 